\title{
O Saci e Procissão dos Mortos - auto-referência fantástica no cinema paulista
}

Laura Cánepa

\section{Resumo:}

O presente artigo propõe uma comparação entre os filmes $O$ Saci (Rodolfo Nanni, 1953) e Procissão dos Mortos (Luis Sérgio Person, 1968), examinando a releitura que o segundo faz do primeiro a partir da visão da resistência à ditadura e da construção de um significado mítico para os jovens brasileiros envolvidos com a guerrilha. O que se deseja, com esta comparação, é rememorar filmes relativamente esquecidos pela historiografia e mostrar que, apesar do atual esquecimento, tratava-se de obras que estabeleceram um importante diálogo entre si, promovendo um curioso elo entre o cinema paulista dos anos 1950 e dos anos 1960, através de um incipiente trabalho com o gênero fantástico.

\section{Palavras Chave:}

Cinema brasileiro, Fantástico, Saci, Procissão dos Mortos, Luis Sérgio Person

\section{Abstract:}

This paper proposes a comparison between the films $O$ Saci (Rodolfo Nanni, 1953) and Procissão dos Mortos (Procession of the Dead, Luis Sérgio Person, 1968), examining the view of resistance to dictatorship and the construction of a mythical significance for young brazilians involved with the guerrillas in Procissão dos Mortos. The goal is to review films relatively forgotten by history and show that despite the current neglect, that works established an important dialogue between them, promoting a curious link between the São Paulo's cinema of the 1950s and 1960s through an incipient work with the fantastic genre.

\section{Keywords:}

Brazilian cinema, Fantastic, Saci, Procession of the Dead, Luis Sérgio Person

A história do cinema fantástico brasileiro ainda está por ser contada. Esse gênero, embora se apresente no cinema nacional de maneira diluída em diversas formas e diferentes períodos, tem também uma trajetória própria em um grupo de filmes que o assumem de maneira declarada e autoconsciente - e o estudo de tal trajetória ainda permanece disperso nas pesquisas sobre o nosso cinema. Mas, quando nos debruçamos, mesmo que superficialmente, sobre os filmes fantásticos brasileiros, notamos que a relação entre eles não é tão dispersa quanto fazem parecer os poucos trabalhos publicados a respeito: o que se observa, ao se colocarem os filmes lado a lado, é que existiram, ao longo do tempo, diálogos, tentativas de estabelecimento de filões de mercado, competição e, em alguns casos, até citações e outros procedimentos intertextuais facilmente identificáveis que dão a essa cinematografia um caráter próprio e inventivo dentro do universo do cinema brasileiro. 
Exemplos evidentes disso podem ser encontrados nas diversas pornochanchadas de horror, muito populares no final dos anos 1970; na maioria dos filmes infantis, inclusive em uma boa parte da filmografia do grupo Os Trapalhões, uma das mais bem-sucedidas comercialmente no país; nas paródias de filmes fantásticos estrangeiros, freqüentes nos anos 1970 e presentes na obra de diretores populares como Amácio Mazzaropi e Adriano Stuart; na filmografia de estrelas da televisão dos anos 1980/90, como Xuxa e Angélica; em séries cinematográficas como Se eu fosse você (2006) e Se eu fosse você 2 (2008), de Daniel Filho, entre muitos outros.

Mas também existem exemplos mais discretos e que exigem observação mais detalhada. Um deles será objeto de análise neste artigo por revelar uma surpreendente continuidade: trata-se da homenagem feita por Luis Sérgio Person, no curta-metragem de horror Procissão dos Mortos (parte do longa-metragem em episódios Trilogia do Terror), produzido por Antonio Pólo Galante e Renato Grecchi, em São Paulo, em 1968, ao longa-metragem infantil O Saci, realizado também em São Paulo, por Rodolfo Nanni, em 1953. A partir da análise proposta neste trabalho, pretende-se demonstrar a evidente relação visual e narrativa entre os dois filmes, e também levantar hipóteses que nos permitam compreender o significado da retomada, feita por Person, de diversos elementos do filme infanto-juvenil de Nanni.

\section{O Saci e o fantástico para crianças}

O Saci foi um marco para o cinema brasileiro por várias razões: foi o primeiro longa-metragem infantil realizado no país, o primeiro inspirado na obra de Monteiro Lobato e também um dos primeiros a reunir um grupo de artistas e intelectuais que teria papel definitivo na constituição de um projeto de cinema nacional, como o cineasta Nelson Pereira dos Santos, que foi assistente de direção do filme, e o pesquisador Alex Viany, gerente de produção. A equipe, chefiada pelo artista plástico Rodolfo Nanni, que até então tinha experiência no cinema apenas como continuísta (do inacabado AGLAIA, de Ruy Santos), contava também com outros profissionais importantes, como o fotógrafo Ruy Santos, o compositor Cláudio Santoro e o montador José Cañizares, além do elenco composto pelas crianças (Paulo Matozinho, como Saci; Livio Nanni, como Pedrinho; Aristela Paula Souza, como Narizinho) e outros atores convidados, como Maria Rosa Ribeiro (Dona Benta), Otávio Araújo (Tio Barnabé) e Benedita Rodrigues (Tia Nastácia).

Concebido como um projeto quase familiar e filmado nos estúdios alugados da Cinematográfica Maristela, em São Paulo, entre 1951 e 1953, o longa foi produzido num sistema independente, mas obteve, depois, significativo sucesso comercial. Inspirado no Saci-Pererê (1), figura folclórica conhecida no Brasil desde o século XVII, e cuja origem está na junção de uma figura da mitologia indígena com elementos das culturas africana e européia, o filme trazia a entidade brincalhona a partir da visão do escritor Monteiro Lobato, que a transformou em personagem recorrente da coleção Sítio do Pica-pau Amarelo, publicada entre 1921 e 1947 - e iniciada justamente com o livro $O$ Saci.

O longa de Rodolfo Nanni contava uma das aventuras das crianças Pedrinho e Narizinho no Sítio do PicaPau Amarelo, quando o menino aprende a caçar sacis e acaba ficando amigo de um deles, que o leva para assistir à "sacizada" (reunião em que dezenas de sacis que se encontram magicamente durante a noite) no meio da floresta. Então, Pedrinho e seu novo amigo descobrem que Narizinho fora petrificada pela maldosa bruxa Cuca, e precisam resgatá-la em uma caverna assombrada, para desespero da vovó Dona Benta e da fiel cozinheira Tia Nastácia.

Como se pode depreender da trama, o filme era dedicado ao público infantil, mas também fazia parte de 
uma proposta mais abrangente de seus realizadores, no sentido de abordar a cultura e a identidade brasileiras no cinema, apresentando soluções estéticas diferentes daquelas que as grandes produtoras cariocas e paulistas (como a Atlântida, a Vera Cruz e a própria Maristela) haviam escolhido. Nesse sentido, o longa chama a atenção por apresentar-se como uma experiência lúdica, que abordou, de maneira quase teatral na direção de arte, e quase documental na direção de fotografia, personagens típicos da literatura e do folclore brasileiros, num recorte que pouco tinha a ver com um cinema "de gênero" internacional pretensamente emulado nos estúdios da época, e estava muito mais ligado à literatura e às representações populares do fantástico na cultura brasileira.

A obra acabou fazendo uma boa carreira comercial, beneficiando-se da popularidade dos textos de Monteiro Lobato e das leis de proteção ao cinema brasileiro, que garantiram a circulação da fita, sobretudo nas cidades do interior do país. O Saci também ganhou alguns prêmios importantes, como o Prêmio Saci de 1954 (concedido pelo jornal O Estado de S. Paulo) e o Prêmio Governador do Estado de São Paulo, no mesmo ano. O filme também teve sua memória relativamente bem preservada, sendo exibido eventualmente na televisão (nas emissoras educativas), e ganhando recentemente uma pouco divulgada edição em DVD, que traz, nos extras, um detalhado documentário sobre a realização do filme.

\section{O fantástico para os jovens em Procissão dos mortos}

Diferentemente de Rodolfo Nanni, que fazia sua estréia como diretor em $O$ Saci, Luis Sérgio Person realizou o curta-metragem Procissão dos mortos num momento de maior maturidade em sua carreira cinematográfica. Então com 33 anos, ele já era conhecido por ter dirigido dois filmes fundamentais para o cinema moderno brasileiro: São Paulo S/A (1965), retrato do desamparo do cidadão comum perante a industrialização iniciada nos anos 1950, e $O$ caso dos irmãos Naves (1967), adaptação de um episódio verídico de injustiça e abuso de poder ocorrido durante o Estado Novo.

A oportunidade para Person fazer seu curta de horror surgiu em 1967, pelas mãos do amigo José Mojica Marins e do então jovem produtor Antonio Pólo Galante. Naquele ano, Mojica e o escritor/roteirista Rubens Francisco Luchetti lideravam o programa de televisão Além, muito além do além, sucesso noturno da TV Bandeirantes, e haviam sido convidados por Galante e Renato Grecchi para fazer um filme baseado em episódios do programa. A idéia dos produtores era reunir três enfant terribles (2) do cinema nacional para realizarem um filme inspirado no programa de TV de Mojica/Luchetti: o próprio Mojica, Person e Ozualdo Candeias, que também acabara de estrear o seminal A Margem (1966).

Candeias, que já fora assistente de direção de Mojica em seu primeiro longa de horror, À meia-noite levarei sua alma, realizado em 1963, dirigiu o curta $O$ Acordo, remotamente baseado no episódio Noite Negra, de Luchetti. A trama original trazia um homem que fazia um pacto com o demônio pela cura da grave doença de sua filha, mas a versão de Candeias, embora se passasse no mesmo cenário de uma cidade interiorana cercada de lendas indígenas e de um catolicismo sincrético, trazia uma mulher que apelava a uma espécie de feiticeiro hippie para fazer com que sua filha se interessasse sexualmente por um fazendeiro que desejava evolver-se com ela. O resultado ficou distante daquilo que geralmente se entende por horror, tratando-se mais de uma reflexão do próprio Candeias em torno das superstições interioranas, da contracultura e das relações de poder e sexo entre homens e mulheres no mundo rural, mas ficou famosa a cena assustadora em que um personagem "encarna" uma entidade sobrenatural num ritual ocorrido em cima de um morro, numa demonstração do domínio do diretor sobre aspectos perturbadores das religiões afro-brasileiras.

Já Mojica dirigiu Pesadelo Macabro, curta muito mais comprometido com as características canônicas do 
gênero horror, tratando do drama de Cláudio (Mario Lima), um homem perturbado com pesadelos premonitórios de ser enterrado vivo - argumento recorrente nas narrativas de horror clássicas como as de Edgar Allan Poe, cuja obra é influência confessa de Luchetti. Apesar da filiação ao horror clássico, porém, o curta carregava no sensacionalismo em torno de rituais de macumba e em cenas de violência sexual, num estilo exagerado e explícito que já era marca do diretor desde seus primeiros filmes, e que se acentuava no final dos anos 1960.

Finalmente, Person, que fora co-roteirista não-creditado de Mojica em seu longa de estréia, o faroeste $A$ Sina do Aventureiro (1957), ficou com Procissão dos mortos, inspirado em episódio homônimo do programa de TV. O episódio original, escrito por Luchetti, mostrava o pavor de um menino que via fantasmas, mas, no curta de Person, tratava-se de fantasmas muito especiais. O diretor se aproveitou da morte do revolucionário argentino Ernesto "Che" Guevara, ocorrida meses antes, na Bolívia, para contar uma estória de horror claramente alegórica, usando como fonte a realidade do país durante a ditadura militar.

No filme, o garoto Quinzinho sai de casa para caçar passarinhos, contrariando as recomendações de sua mãe. No mato, encontra um guerrilheiro morto, cujo corpo em decomposição segura uma metralhadora e exibe um sorriso sardônico. A polícia é chamada, o corpo é recolhido e exposto à curiosidade pública, mas os moradores da cidade, insatisfeitos com as explicações das autoridades (que negam a possibilidade de o guerrilheiro ser Che Guevara e dizem não ter encontrado nenhuma metralhadora junto ao corpo), começam a desconfiar de que o menino esteja ajudando outros guerrilheiros ainda escondidos na floresta.

Então, o operário Miguel (Lima Duarte), pai do menino, ofendido após uma discussão com seus companheiros de bar, decide ir à floresta à noite para comprovar que não há outros guerrilheiros por lá, levando como arma apenas o símbolo da paz pendurado no pescoço. Quando ele chega à pedreira no meio da floresta, porém, os guerrilheiros, na forma de dezenas de fantasmas de Che Guevara, cercam-no e matam-no a golpes de metralhadora no coração - exatamente de onde pendia o símbolo da paz. No dia seguinte, Quinzinho volta para o mato - desta vez, não mais em busca de passarinhos, mas dos próprios guerrilheiros. Ele encontra a metralhadora, entrega a um deles, que a devolve carregada e sugere que ele comece a experimentá-la. O menino, então, atira em direção à câmera. Fim.

Evidentemente, Procissão dos Mortos contém uma corajosa alegoria política, ao sugerir que a revolução seria irresistível aos jovens. Também é notória, no filme, a preocupação do diretor em ligar seu trabalho às experiências do cinema moderno brasileiro da época, como se percebe num certo olhar neo-realista reconhecível no uso de locações reais e na opção por um tipo de fotografia (feita por Oswaldo de Oliveira), que não interferia na luz natural. Outro elemento interessante que surge no filme é o uso da música popular, em particular quando um dos personagens entoa a canção Pra onde vai, valente? , de Manezinho Araújo (3), composta em 1934, cujo refrão repete "pra onde vai, valente? eu vou pra linha de frente" - canção que é seguida pela entrada de um personagem bêbado cantando o Hino do Exército, no qual se destacam as palavras "a guerra só nos causa dor, a paz queremos com fervor". Com isso, Procissão dos mortos pode ser visto, de certa forma, como um documento das tensões daquele período. Mas também é, inquestionavelmente, um filme de horror - possivelmente o mais interessante e curioso de Trilogia de Terror, justamente pela (rara) capacidade de reunir o universo de um gênero geralmente tido como retrógrado (por sua rejeição à alteração da ordem vigente) ao discurso político engajado pela revolução e pelas mudanças sociais.

O filme ficou pronto em março de 1968. Depois de marcar o lançamento para 22 de abril, no Rio de Janeiro, e 13 de maio, em São Paulo, Galante começou a agendar sessões especiais para os críticos, que mostraram simpatia pelo curta de Person e enorme rejeição ao filme de Mojica (BARCINSKI, FINOTTI, 1998: 211). No dia 09 de abril de 1968, porém, a Censura proibiu o filme, o que levou Renato Grecchi à 
Brasília para negociar com os censores. Ele acabou conseguindo liberar o filme com apenas quatro cortes, que prejudicaram particularmente os filmes de Person e de Mojica.

Ainda assim, Trilogia de Terror teve uma recepção razoável entre os críticos. Segundo Barcinski e Finotti (1998: 217), por exemplo, o Estadão teria publicado, na estréia do filme em São Paulo, um texto com o título: Tudo bem, antes de Mojica (4), o que indicava que a estratégia criada por Grecchi de chamar Candeias e Person fora fundamental para garantir a circulação da fita. Mais ou menos na mesma linha da manchete citada do Estadão, seguiram quase todos os críticos do Rio e de São Paulo, que elogiaram particularmente o filme de Person e se mostraram incomodados com as cenas de violência sexual do filme de Mojica. Um dos únicos entusiastas da obra inteira foi Salvyano Cavalcante de Paiva, que escreveu, no jornal carioca Correio da Manhã, um de seus muitos libelos ao cinema de entretenimento:

A inteligência de Trilogia de Terror foge, talvez, à compreensão de apenas duas espécies de cinespectadores: os falsos puritanos, obnubilados por uma neblina de preconceitos intransponíveis, que rejeitam aprioristicamente o erotismo e a violência intrínseca de seres humanos projetados em personagens de criação artística legítima (...); os falsos estetas de um cinema supostamente engajado em inovações formais, a mais importante das quais seria o distanciamento e o enclausuramento do público. (PAIVA, apud BARCISNKI; FINOTTI, 1998: 213).

A relativa simpatia dos críticos, porém, não se refletiu nas bilheterias, o que transformou o projeto num mau negócio para seus produtores. Com isso, quase toda a equipe (à exceção de Mojica) ficaria longe do cinema de horror nos anos seguintes. No entanto, aos olhos de hoje, e considerando-se a trajetória inconstante do horror no cinema brasileiro, Trilogia de Terror marca um momento em que o gênero foi experimentado por realizadores influentes no cinema nacional, que, em outras circunstâncias históricas, poderiam ter indicado caminhos consistentes para o gênero em nossa cinematografia. E, além de marcar esse momento importante do cinema de horror brasileiro, o filme também traz, no episódio de Person, uma curiosa homenagem a outro "clássico" do cinema fantástico brasileiro e paulista: $O$ Saci, de Rodolfo Nanni, conforme se examina a seguir.

\section{O Saci e Procissão dos Mortos: parentesco inegável}

Embora os filmes de Nanni e Person tivessem intenções estéticas, mercadológicas e políticas completamente diferentes e estivessem ligados a contextos históricos igualmente distintos, ambos assumiram claramente o gênero fantástico. No primeiro caso, através de uma estória infantil com final feliz; no segundo, através de uma perturbadora estória de horror. Nesse sentido, cabe salientar que o gênero fantástico, tanto em suas primeiras expressões literárias quanto em seus desdobramentos nas mais diversas mídias, sempre abarcou uma grande e variada gama de situações que tinham em comum a introdução de um elemento "sobrenatural" ao mundo natural conhecido, o que poderia gerar inúmeras abordagens.

Mas, evidentemente, além dessa relação de gênero, os filmes têm muito mais em comum. A idéia da fuga para a floresta com o objetivo de buscar algum animal ou entidade mítica da natureza, que dá o plot dos dois filmes, é originária dos contos populares (como os de fadas) e um dos motivos mais antigos e frequientes nas estórias fantásticas. Além disso, é notória a referência imagética feita por Person ao filme de Nanni na sequiência em que Quinzinho entra na floresta, o que se evidencia na cena em que o menino bebe água no rio sem usar as mãos. Neste momento, Procissão dos Mortos praticamente "decalca" o plano do filme de $\mathrm{O} S \mathrm{Saci}$, conforme se pode verificar nas imagens a seguir, que reproduzem fotogramas 
originais dos filmes.
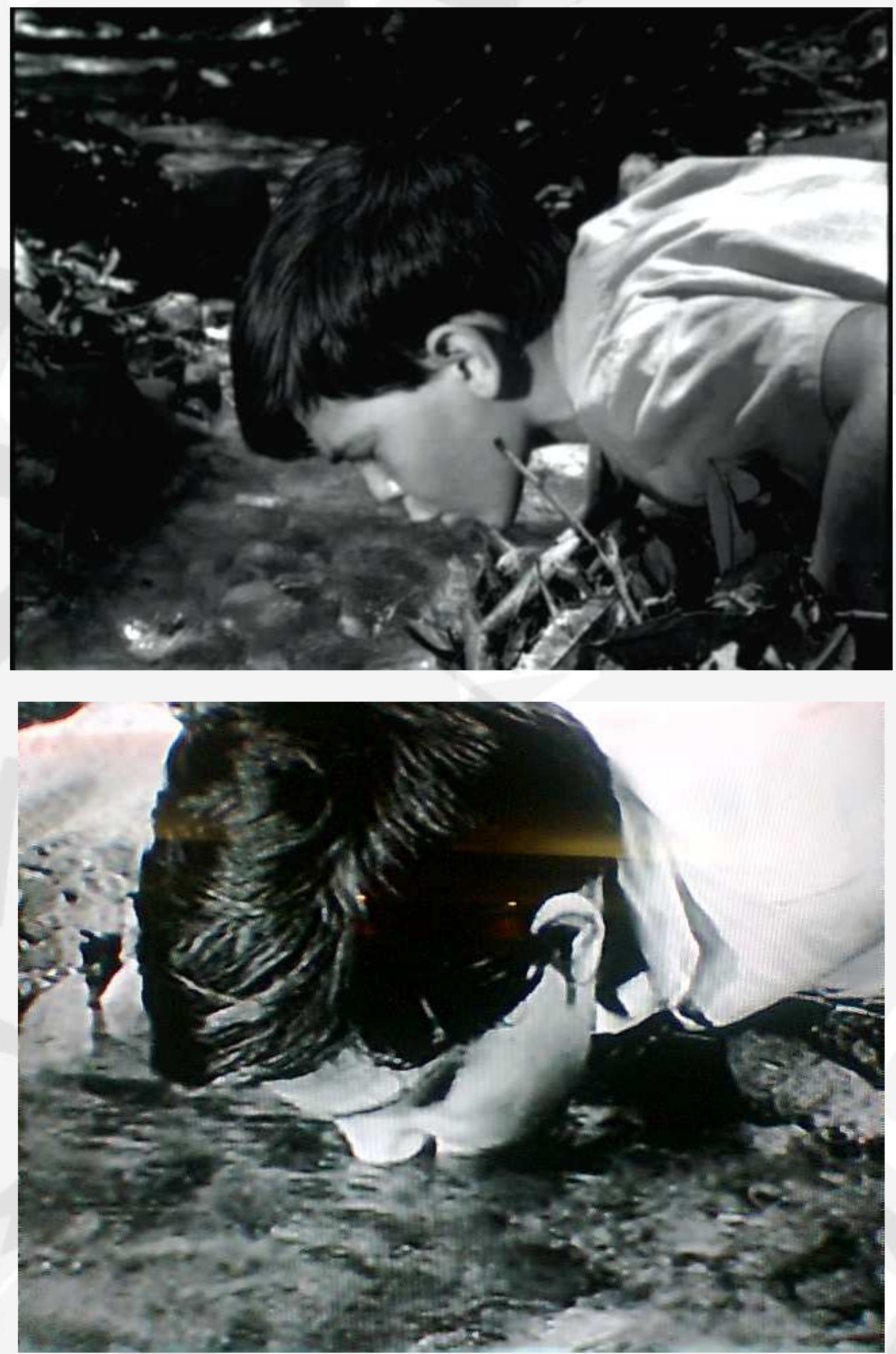

A citação quase literal, no entanto, parece ser apenas uma "chave" oferecida pelo diretor para a seqüência em que surgem os fantasmas de Che, e que dá o clímax de Procissão dos Mortos. Nesta, a referência a $O$ Saci fica mais evidente e mais orgânica, pois, ao reunir os guerrilheiros sobrenaturais que atacam o pai de Quinzinho impiedosamente, Person parece sugerir um paralelo com a "sacizada" testemunhada pelo garoto Pedrinho em $\mathrm{O}$ Saci. Como se pode notar nas imagens a seguir, que reproduzem fotogramas dos 
dois filmes, ambos trazem os personagens mágicos surgindo um a um, no meio da noite, em algum lugar misterioso e pouco acessível, para depois mostrá-los juntos em ação, numa reunião ao mesmo tempo fantástica e caótica. O resultado narrativo dessa reunião, no entanto, como já foi relatado, é diferente em cada um dos filmes, marcando justamente sua diferença fundamental.
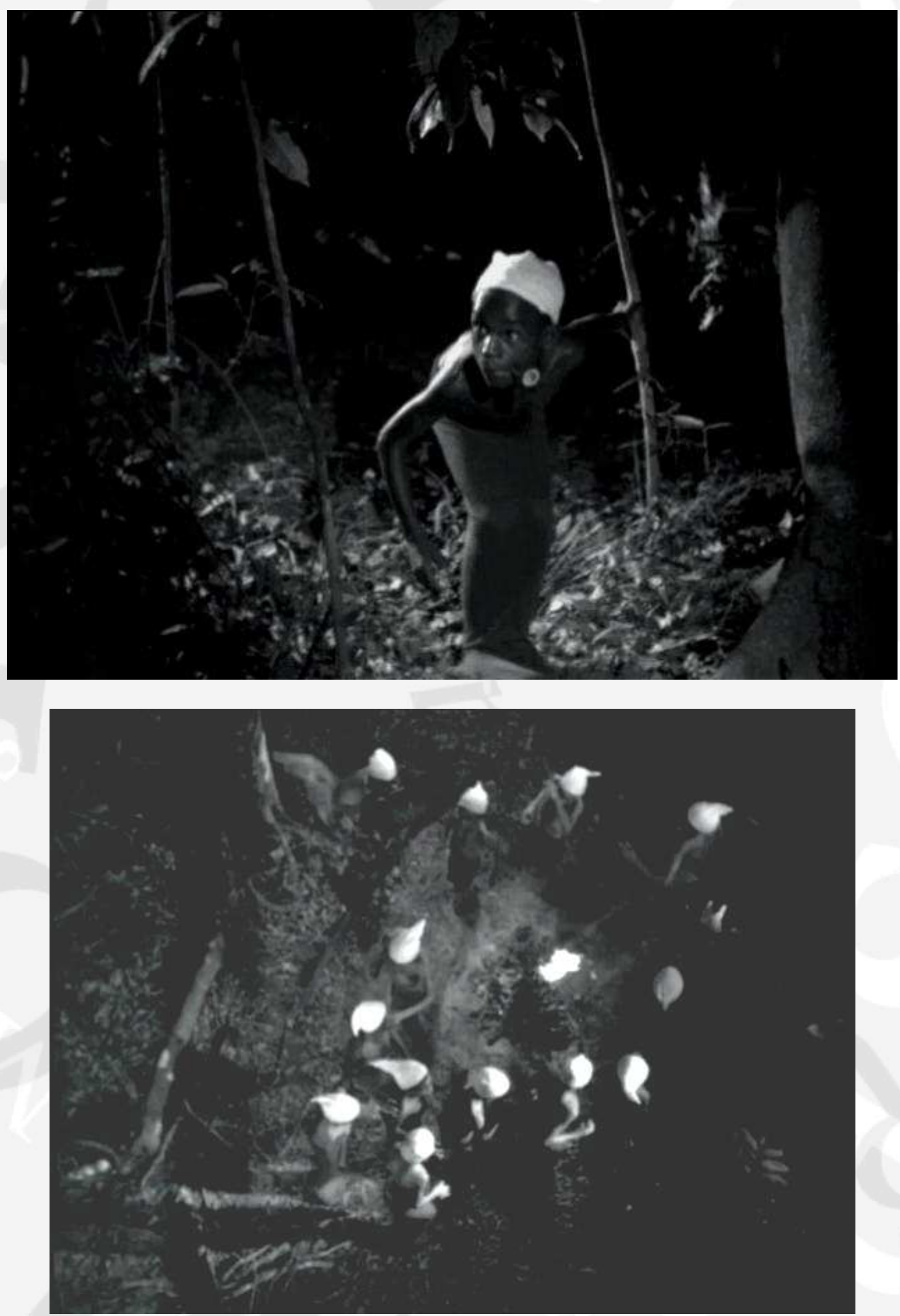

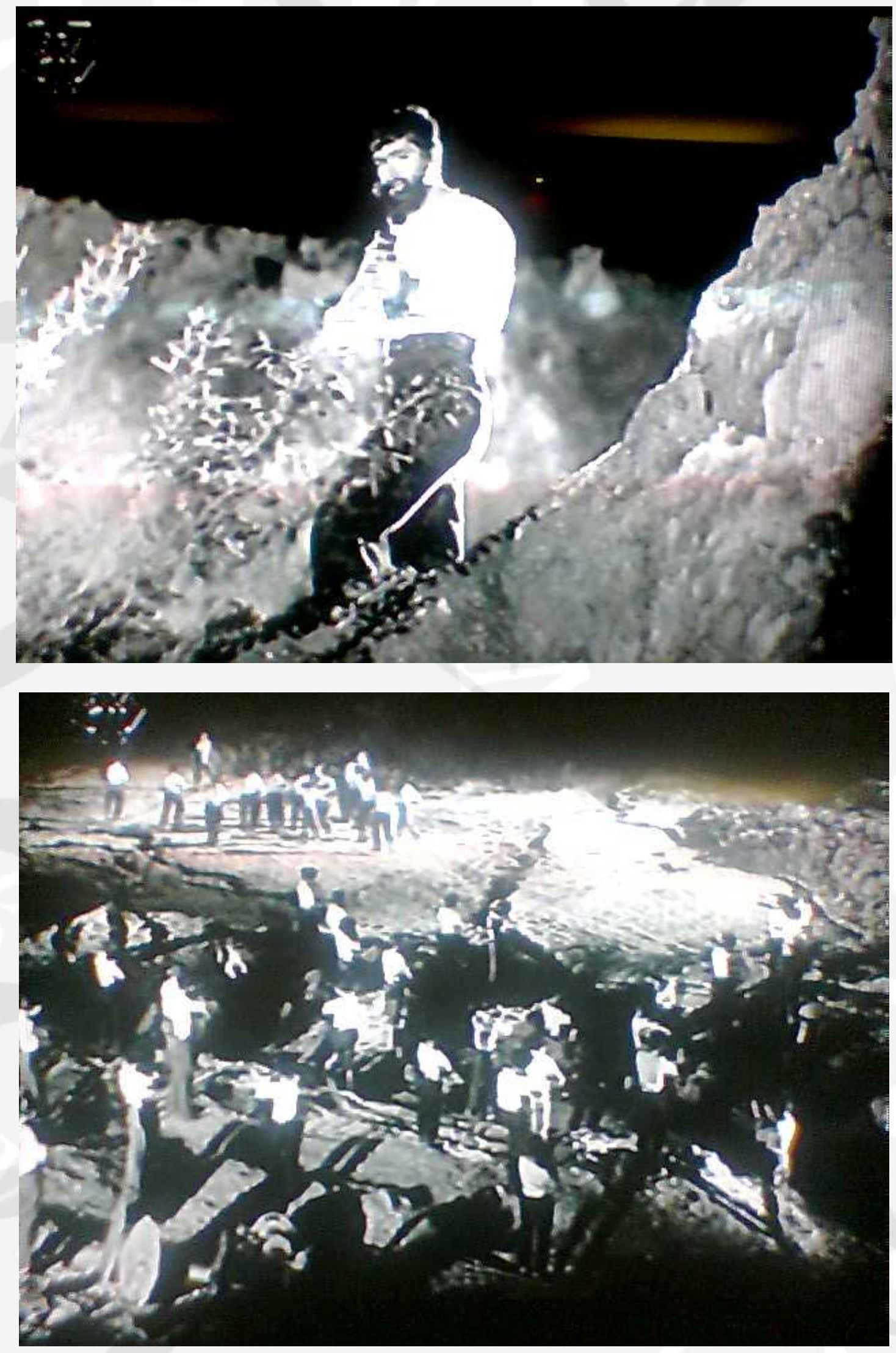

Assim, Procissão dos Mortos talvez possa ser visto como uma "atualização histórica" de $O$ Saci, feita 
num momento particularmente dramático da história brasileira. Aparentemente, na visão de Person, o inocente passeio de Pedrinho, nos anos 1950, em um mundo rural e selvagem no qual podia se encontrar romanticamente com entidades da natureza e com um Brasil idílico, não era mais possível em 1967. Agora, o menino precisava lidar com uma realidade mais urgente, mais violenta e mais adulta, mas podia ter uma conduta igualmente romântica ao unir-se aos guerrilheiros na floresta em busca de um mundo menos autoritário e que não tivesse a paz silenciosa como ideal a ser buscado. Se o Saci de Nanni podia ser visto como o divertido e rebelde amigo das crianças, que poderia mostrar-lhes uma nova vida de alegria e fantasia, os fantasmas dos guerrilheiros também traziam uma alternativa mítica de libertação e, ao mesmo tempo, o drama da nova situação.

Nesse sentido, impressiona o domínio do diretor sobre uma atmosfera de medo construída num ambiente rural já contaminado pelo desenvolvimento urbano (pois trata-se de uma região devastada por uma pedreira na qual o pai do menino e seus companheiros trabalham), e no qual o recrudescimento das tensões políticas é evidenciado junto com o horror. Além dessa metáfora sobre a guerrilha, a evidente "citação interna" do cinema paulista mostra a consciência de Person sobre duas questões fundamentais para o cinema de sua época. A primeira era o contato entre o trabalho engajado dos anos 1960 e as experiências relacionadas à luta pelo cinema nacional e popular dos anos 1950. A segunda, o fato de que, tanto em seu filme como no de Nanni, tratava-se de experiências de popularização do cinema brasileiro através do gênero fantástico.

Não por acaso, Person seguiria fazendo interessantes experiências relativas ao cinema de gênero, sem deixar de lado o engajamento político e a crítica social. Seu faroeste Panca de Valente (1968), por exemplo, paródia cômica dos filmes hollywoodianos e italianos, vinha carregado de sátira social e política, com seu herói desajeitado e seus vilões ridículos. Também a pornochanchada Cassy Jones, o magnífico sedutor (1972), com seu protagonista que começa a se cansar do assédio das mulheres, trazia a reflexão sobre as mudanças no comportamento sexual iniciadas nos anos 1960. Rever a filmografia de Person a partir dessas experiências ajuda a jogar novas luzes sobre sua obra, fazendo com que sejam levadas em consideração as possibilidades criativas e políticas do uso dos gêneros cinematográficos canônicos pelo cinema brasileiro. Nesse conjunto, Procissão dos mortos desponta como uma das experiências mais radicais e bem-sucedidas, marcando um dos últimos "respiros" antes do recrudescimento da ditadura militar no final de 1968, com a instituição do AI-5 e de suas nefastas conseqüências para a vida e a cultura nacionais.

Imagem 3: Cena da "sacizada" descoberta Imagem 4: Cena da "sacizada" descoberta por Pedrinho em por Pedrinho em $\mathrm{O}$ Saci, de Rodolfo Nanni $O$ Saci, de Rodolfo Nanni

Imagem 5: Cena de Procissão dos mortos, de Imagem 6: Cena de Procissão dos mortos, de Luis Sérgio Luis Sérgio Person. Person. 


\section{Bibliografia:}

BARCINSKI, André; FINOTTI, Ivan. Maldito - a vida e o cinema de José Mojica Marins, o Zé do Caixão. São Paulo: Editora 34, 1998.

CANEPA, Laura Loguercio. Medo de quê? - Uma História do Horror nos Filmes Brasileiros. Campinas: Instituto de Artes da Universidade de Estadual de Campinas, 2008. Tese de Doutorado em Multimeios.

RAMOS, Fernão; MIRANDA, Luis Felipe. Enciclopédia do cinema brasileiro. São Paulo: SENAC, 2000.

TODOROV, Tzvetan. Introdução à literatura fantástica. 2. ed. São Paulo: Perspectiva, 1992.

\section{Referências filmográficas}

SACI, O (1953, São Paulo, P\&B, 64 minutos)

Produção: Artur Neves

Direção: Rodolfo Nanni

Roteiro: Rodolfo Nanni e Artur Neves, baseados nos personagens de Monteiro Lobato

Assistente de direção: Nelson Pereira dos Santos

Gerente de Produção: Alex Viany

Direção de Fotografia: Ruy Santos

Montagem: José Cañizares

Cenografia: Teresa Nicolau

Música original e regência: Cláudio Santoro

Companhia Produtora: Brasiliense Filmes

Elenco: Paulo Matosinho, Lívio Nanni, Aristela Paula Souza, Olga Maria Amâncio, Maria Rosa Ribeiro, Benedita Rodrigues, Otávio Araújo

TRILOGIA DE TERROR (1968, São Paulo, P\&B, 92 minutos)

Produção: Antônio Pólo Galante e Renato Grecchi 
Direção: Ozualdo Candeias, Luiz Sergio Person, José Mojica Marins

Montagem: Sylvio Renoldi

Companhia Produtora: Produtora Nacional de Filmes, Produções Cinematográficas Galacy Ltda, Cia. Cinematográfica Franco-brasileira

\section{Procissão dos mortos}

Direção e Roteiro: Luis Sergio Person, com base em texto de R.F.Luchetti

Fotografia e câmera: Osvaldo de Oliveira

Elenco: Lima Duarte, Cacilda Lanusa, Waldir Guedes, Carlos Alberto Romano

\section{Notas:}

(1) Do tupi-guarani Çao-Sy (olho mau) e Perereg (saltitante).

(2) Segundo Barcinski e Finotti, biógrafos de Mojica, tudo começou em outubro de 1967, quando Galante teria procurado o diretor com a intenção de fazer a continuação do seu filme Esta noite encarnarei do teu cadáver, que estreara no começo daquele mesmo ano. O negócio, porém, não vingou, em função da negativa do produtor de Esta noite..., Augusto Pereira. Então, Mojica e Galante teriam decidido fazer um filme de horror em episódios baseados no programa da TV Bandeirantes, mas Galante precisava obter financiamento do INC (Institudo Nacional de Cinema) e sabia que poderia ter problemas em função da fama de Mojica como diretor de filmes excessivamente violentos e escatológicos. Para tentar resolver o problema, ele procurou o veterano produtor Renato Grecchi, que se juntou à dupla e propôs que fossem chamados para integrar o projeto os diretores Candeias e Person, que haviam, recebido prêmios do INC por A Margem e $O$ Caso dos Irmãos Naves, respectivamente. Com isso, o projeto foi aprovado. (Cf. In. BARCINSKI; FINOTTI, 1998: 204-205).

(3) Manuel Pereira de Araújo, conhecido como Manezinho Araújo (1913-1993), pernambucano de Cabo de Santo Agostinho, foi cantor, compositor, jornalista e pintor, e teve várias de suas músicas eternizadas por Luiz Gonzaga e Jackson do Pandeiro.

(4) Os episódios do filme são ordenados da seguinte maneira: O acordo, Procissão dos mortos, Pesadelo macabro.

\section{Mini Currículo :}

Doutora em Multimeios pela Universidade de Campinas (Unicamp). Professora do Mestrado em Comunicação da Universidade Anhembi Morumbi (MeCom - Anhembi Morumbi). 